\title{
Research protocol for the study of hyperinsulinism in infancy
}

\begin{abstract}
Hypoglycemia is an event well described in pediatrics population. However, recurrent episodes of severe hypoglycemia and early start are not well defined. Although hypoglycemia may be difficult to prove, the possibility of hyperinsulinism should be considered. Being an early and certainly diagnosis, critical to prevent permanent brain damage or death.
\end{abstract}

Volume 2 Issue 3 - 2015

\section{Campeni Susana}

Htal de Clinicas, Universidad de Buenos Aires, Argentina

Correspondence: Campeni Susana, Paediatric Endocrinology Htal de Clinicas, Universidad de Buenos Aires, Argentina, Tel +541147018175, Email susanacampeni@hotmail.com

\section{Introduction}

Hypoglucemia is a well described event in pediatrics population. Is understood as the discovery of lower plasma glucose $40 \mathrm{mg} / \mathrm{dl}$, for asymptomatic episodes; and under $50 \mathrm{mg} / \mathrm{dl}$ for symptomatic. However, recurrent episodes of severe hypoglucemia and early start are not well defined. Hypoglycemia remains one of the most confusing and controversial issues in pediatric medicine, in relation to pathophysiology and therapeutic mechanisms.

Moreover, symptomatology is not specific or pathognomonic in this population. Although hypoglycemia may be difficult to prove, the possibility of hyperinsulinism should be considered. Being an earlier and certainly diagnosis, critical to prevent permanent brain damage or death.

\section{Objectives}

a. Identify unusual causes of hypoglycemia in the practice of Pediatric Endocrinology.

b. Defining primary and secondary causes of hyperinsulinism.

c. Show the hyperinsulinism per-se, such a situation which can reduce the availability of alternative substrate for brain metabolic pathways, causing harmful and predictable consequences on brain metabolism.

d. Underline the vital importance of early diagnosis, and appropriate and energetic treatment of childhood hypoglycemia.

e. Identify persistent primary forms of Hyperinsulinemic Hypoglycemia of infancy.

\section{Exclusion criteria for study hyperysulinism:}

a. Presence of ketonemia or ketonuria.

b. The Ketotic Hypoglycemia is the most common form of childhood hypoglycemia, between 18 months and 5 years, evolving into spontaneous remission between 8 and 9 years

c. Neonatal transient forms of hyperinsulinism. d. As in the case of a Diabetic mother.

e. Hyperinsulinism forms of drug- induced or toxic side.

f. As in the case of surreptitious insulin application, or hypoglycemic deliberate consumption.

\section{Hyperinsulinism study scheme thorough medical his- tory for each patient}

This allows us to detect Hypoglycemia secondary to neonatal not transitional hyperinsulinism; as seen in: the small for gestational age newborns; children of toxemic mothers or birth asphyxia. There are other congenital beginning forms of neonatal hypoglycemia, such those seen in Beckwith-Wiedemann Syndrome, with macrosomic newborns, umbilical hernia, hepatomegaly, and two-sided ear groove.

Beckwith-Wiedemann Syndrome (chromosome duplication 11), and Trisomy $11 \mathrm{p} 15$ are included within the dominant forms of congenital hyperinsulinism.

By other way, the presence of profound hypoglycemia regardless of their presentation; its rapid development, even with lower fasting three hours ; the need for significant flows of glucose to stabilize blood sugar; the erratic or refractory response to conventional therapy; insulin levels within the normal range, though inappropriately elevated for patient blood glucose; an index insulin/glucose greater than 0,25 as defined by hyperinsulinism; test positive stimulus Glucagon response demonstrates the presence of intact mechanisms gluconeogenesis; and finally a successful response to therapeutic trial with Diazoxido, support the Primary and Permanent form of Hyperinsulinism.

\section{Detailed physical examination}

Hepatomegaly: It leads us to a glycogen storage disease.

Microphallus: It will direct us to a Growth Hormone Deficiency, counter regulatory in glucose metabolism.

Cutaneous - mucous pigmentation: Acanthosis may be present in pre- pubertal lean subjects, with insulin receptor mutation.

Statural normal curve in percentiles for age and sex: It will help us rule out Growth Hormone Deficiency. 


\section{Dosages at baseline}

It involves the removal of a single blood sample, considered critical. Critical because it must be taken in the context of hypoglycemia.

\begin{tabular}{|c|c|}
\hline $\begin{array}{l}\text { Samples to be } \\
\text { taken }\end{array}$ & Expected Respond \\
\hline Glycemia & Lowered \\
\hline Insulin & High for Glycemia \\
\hline $\begin{array}{l}\text { Nonesterified Free } \\
\text { Fatty Acids }\end{array}$ & $\begin{array}{l}\text { Lowered (Inversely Proportional to Insulin } \\
\text { behavior) }\end{array}$ \\
\hline $\begin{array}{l}\text { Betahydroxybu- } \\
\text { tyrate }\end{array}$ & Lowered \\
\hline Cortisol & $\begin{array}{l}\text { May be increased (by stress); or Low, Involve- } \\
\text { ment the adrenal axis }\end{array}$ \\
\hline Growth Hormone & $\begin{array}{l}\text { Decreased in pituitary disease with growth } \\
\text { hormone deficiency }\end{array}$ \\
\hline $\begin{array}{l}\text { Insulin growth } \\
\text { factor- like type I }\end{array}$ & $\begin{array}{l}\text { Very high values make us suspect the presence } \\
\text { of producing tumors (insulinomas) }\end{array}$ \\
\hline Lactic acid & Its increase leads us to deposit disease \\
\hline Ammonium & $\begin{array}{l}\text { Its increase is observed in metabolic disorders } \\
\text { with liver failure, or Hyperinsulinism -Hyperam- } \\
\text { monemia syndrome }\end{array}$ \\
\hline
\end{tabular}

The expected responses, mentioned above, are found in the Primary Persistent Hyperinsulinemic Hypoglucemia of infancy

\section{Stimulation tests for the diagnosis of hyperinsulinism}

Bottle test: (milk alone, sugar free) It involves protein intake leading, to successive dosages, to a significant decrease in blood glucose. This is observed in sensitive leucine forms of hyperinsulinism. But we must make a new confirmatory test without the contribution of leucine in the diet.

If adequate glycemic control is not achieved by preventing leucine , we must rule out other causes of Hyperinsulinemic Hypoglycemia.

Glucagon test: Successive dosages of blood glucose after the administration of intravenous Glucagonn $(0,3 \mathrm{ml})$. It will be seen, in remote times, a significant decrease in blood glucose.

\section{Therapeutic trial with Diazoxide}

Only for primary and permanent forms of Hyperinsulinism, by oral administration of Diazoxide at $10 \mathrm{mg} / \mathrm{kg} / \mathrm{day}$. Diazoxide acts as a specific agonist sensitive $\mathrm{K}^{+}$channels. Use as conservative treatment.

In the case of sensible forms there will be a satisfactory response, with glycemic control within normal parameters. Resistant forms, wi- thout satisfactory response to Diazoxide, require continuing patient study, using the following therapeutic trial.

\section{Therapeutic trial with octeotride synthetic analogue of somatostatin)}

It is indicated in those cases resistant to Diazoxide, with early onset of severe symptoms. The Octeotride was given in three or four subcutaneous injections, or as a continuous infusion. No growth arrest was observed in any patient, as published in the literature. This therapeutic test is a pre-pancreatectomy step, practiced as partial pancreatectomy. Favorable response to Octeotride therefore, it has prevented the use of this practice.

\section{Imaging test}

Necessary for the workup of focal forms, such as:
a. Beta cell adenoma.
b. Insular adenoma.
c. Nesidioblastosis.

\section{Molecular Study}

For diagnosing genetic defects of Beta cell regulation. Both, recessive forms (mutations of SUR/KIR 6.2, or KTP gene), as dominant (Beckwith -Wiedemann Syndrome; or Hyperinsulinism Syndrome associated with Hyperammonemia). Subunit mutations in forming the ATP sensitive $\mathrm{K}^{+}$channel, leading to insulin hypersecretion. Moreover, the focus and self-limiting forms of Hyperinsulinism would be determined by islet cell apoptosis. Mutations of both SUR and KIR 6.2 gene encoding $\mathrm{K}^{+}$channel components are responsible for the regulation of insulin release. Therefore both SUR and KIR 6.2 are required for normal regulation of the Beta cells activity $\left(\mathrm{K}^{+}\right.$ATP channel-dependent) and insulin secretion. Children carrying Hyperinsulinemic Hypoglycemia have no channels $\mathrm{K}^{+}$.

\section{Conclusion}

While Primary Persistent Hyperinsulinemic Hypoglycemia in childhood is rare, it should be considered in a child or infant with refractory hypoglycemia. It is vital to expand the diagnostic scheme and implement an early and aggressive therapy, in all early-onset or refractory behavior hypoglycemia.

\section{Acknowledgements}

None.

\section{Conflicts of interest}

The author declares there is no conflicts of interest. 